\title{
Moment curvature analysis of concrete flexural members confined with CFRP grids
}

\author{
A. Michael \& P. Christou \\ Department of Civil Engineering, Frederick University, Cyprus
}

\begin{abstract}
The moment-curvature (M- $\Phi)$ diagrams define the maximum capacity of structural elements that are primarily subjected to bending moments and therefore their failure mode is flexural. The moment-curvature diagrams are also used to assess the ductility of structural elements and are therefore very important for the determination of the amount of plastic energy a structural element can absorb. One way of improving the reinforced concrete (RC) members is the confinement of concrete with FRP composites. The work presented in this paper includes the development of moment curvature diagrams for RC members using a fiber model. The RC members were designed as compression controlled members meaning that their failure initiates in the concrete prior to yielding of the steel tension reinforcement. These types of members have limited ductility. The introduction of a specific amount of Carbon Fibre Reinforced Polymer (CFRP) composite grid as confining reinforcement improves the ductility of the RC members by as much as $30 \%$. The results from the fiber model are compared to available results from an experimental program conducted to evaluate the experimental improvement of the ductility of compression controlled members. The experimental and analytical results are a good match indicating that the fiber model is accurate and can be used to develop the moment-curvature diagrams of RC members confined with a CFRP composite grid.
\end{abstract}

Keywords: CFRP grid, concrete confinement, moment curvature, ductility.

\section{Introduction}

Compression controlled steel reinforced members, fail through crushing of concrete and therefore lack the ductility that is associated with yielding of the 
reinforcement. This is due to the fact that concrete as a material does not behave in a ductile manner. Concrete may exhibit limited ductility (also called pseudo ductility) but this ductility varies depending on the aggregate material and the strength of concrete used. High strength concrete is more brittle than low strength concrete and therefore for high strength concrete the pseudo ductility diminishes. This is similar to concrete members reinforced with Fibre Reinforced Polymer (FRP) composites. FRP reinforcing bars when loaded in tension, exhibit linear stress-strain behaviour up to rupture. There is no yield point and associated plateau to provide a ductile response when used as tensile reinforcement in concrete. Rooney and Taylor [1], Toutanji and Deng [2], and Grace et al. [3] found that the post cracking beam behaviour was linear to failure in concrete beams reinforced with glass FRP rods which shows the lack of a yield plateau and therefore the lack of a ductile response. There have been attempts to improve the ductility of FRP with little or no success. If these members are designed in such a way in order to fail through concrete crushing limited ductility may be exhibited much like in the case of compression controlled members.

Therefore, the focus of improving member ductility should be on the concrete for compression controlled members. If the concrete in the compression zone of a flexure dominated member is confined then degradation of the compression zone at capacity is delayed, resulting in a more ductile response.

Carbon Fibre Reinforced Polymer (CFRP) composite grids have been used to reinforce concrete decks and beams for both strength and crack control [4-8]. The CFRP composite grid has been used as confinement reinforcement with promising results. In a series of cylinder tests conducted by Michael et al. [9] it was found that the crushing strain of CFRP composite grid confined concrete was more than 2 times higher than the crushing strain of unconfined concrete.

The advantage that the CFRP composite grid has over the use of FRP composite wraps that have been used for both confinement of concrete or strengthening of concrete members is the ability of the CFRP composite grid to be embedded in the concrete. The CFRP composite grid has openings that allow concrete to flow through thus can be embedded in the member during construction. This also provides environmental protection to the CFRP composite since the composite is not exposed to the natural elements that can cause environmental degradation to the FRP composite.

Moment-curvature diagrams are used to assess the ductility of structural elements and are therefore very important for the determination of the amount of plastic energy a structural element can absorb. The research presented in this paper evaluated the moment-curvature response of compression controlled RC members confined with CFRP composite grid with the use of a fiber model that plots the moment-curvature diagram of such sections.

\section{Experimental investigation}

The unique application of the CFRP composite grid as confining reinforcement was evaluated with the construction of two beams. Beam 1 had no CFRP composite grid tubes and served as the control beam and beam 2 had two CFRP 
composite grid tubes placed in the compression zone. Details of the dimensions, amount and location of steel reinforcement and CFRP composite grid tubes are provided in Figures 1 and 2. The CFRP composite grid was formed into a circular tube using a $152 \mathrm{~mm}$ diameter plastic pipe and was held in place by a thin rope wrapped around the tube along its length.

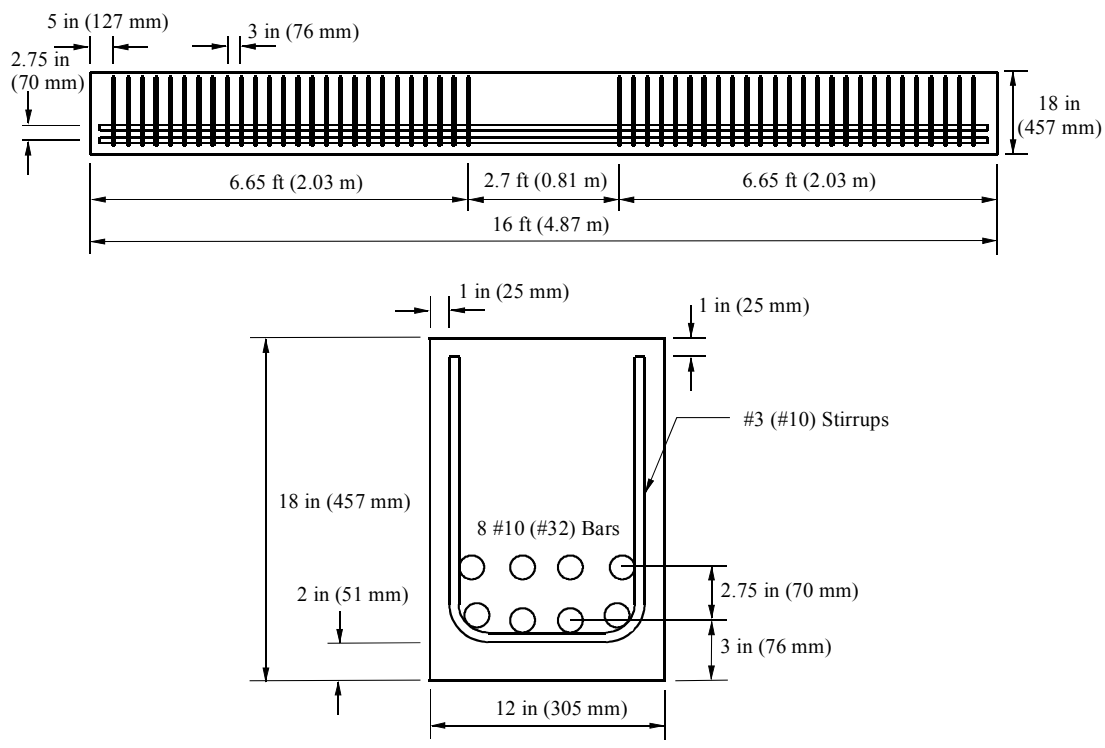

Figure 1: Details of control beam.

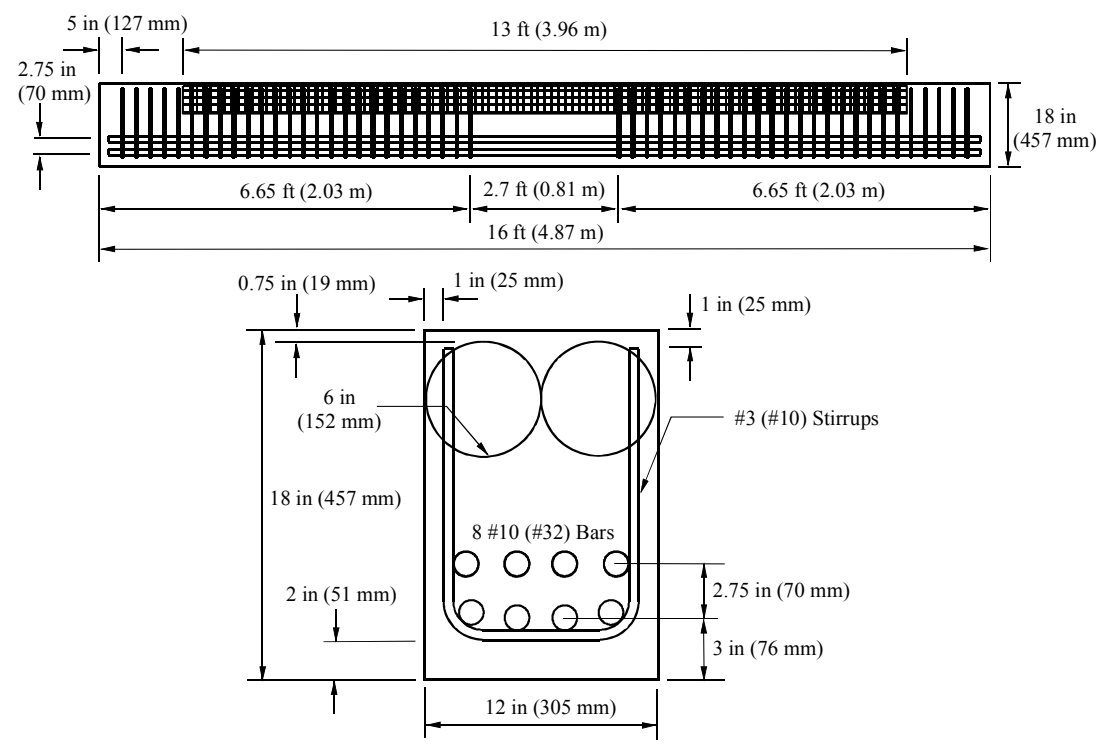

Figure 2: Details of grid beam. 
The beams were tested in a simply supported four-point bending configuration (see Figure 3) in displacement control mode, that is, a constant displacement rate was applied independently of the amount of load. The span length between the two supports was $4.27 \mathrm{~m}$, whereas the total length of the beams was $4.87 \mathrm{~m}$.

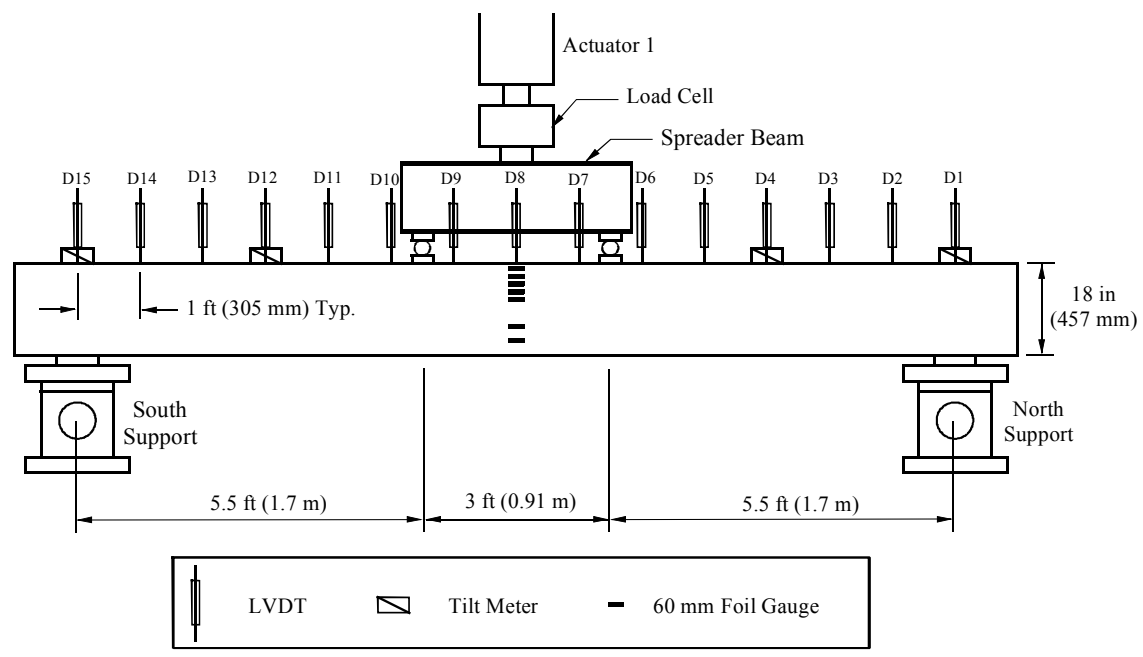

Figure 3: $\quad$ Test set-up.

\section{Moment curvature analysis}

The moment-curvature (M- $\Phi)$ diagrams of the beams were calculated based on experimental data and also based on a theoretical fiber model.

The experimental moment-curvature diagrams were calculated based on the displacement profile curves at increasing loads. The displacement profile equation was generated by fitting a $3^{\text {rd }}$ order polynomial line to the displacement profile curves. The fitted lines were in good agreement with the displacement data (average $\mathrm{R}^{2}=0.99$ ). The polynomial displacement profile equation of the beam was used to determine the curvature at specific points along the length of the beam. The second derivative of the polynomial displacement profile equation is the curvature equation.

The M- $\Phi$ curves of the beams were calculated using a fiber model. The compression zone of the tube beam was separated into two regions with regard to concrete properties. The first region was the concrete cover on top of the CFRP grid tubes and the second region was from the neutral axis to the top of the CFRP grid tubes (see Figure 4). The first region was extended approximately 0.25 in. $(6.5 \mathrm{~mm})$ below the top of the CFRP grid tubes to account for the unconfined concrete at the sides and between the grid tubes. The first region was assigned unconfined concrete properties and the second region confined properties. The concrete area from the neutral axis to the bottom of the grid tubes was unconfined but was treated as confined concrete for simplicity and because 
the strains in that area close to the neutral axis were small and therefore the effect on the strength was minor. The unconfined region was divided into one rectangular layer while the confined region was divided into eight rectangular layers. For the control beam, the compression zone was treated as an unconfined concrete region and was divided into eight layers.

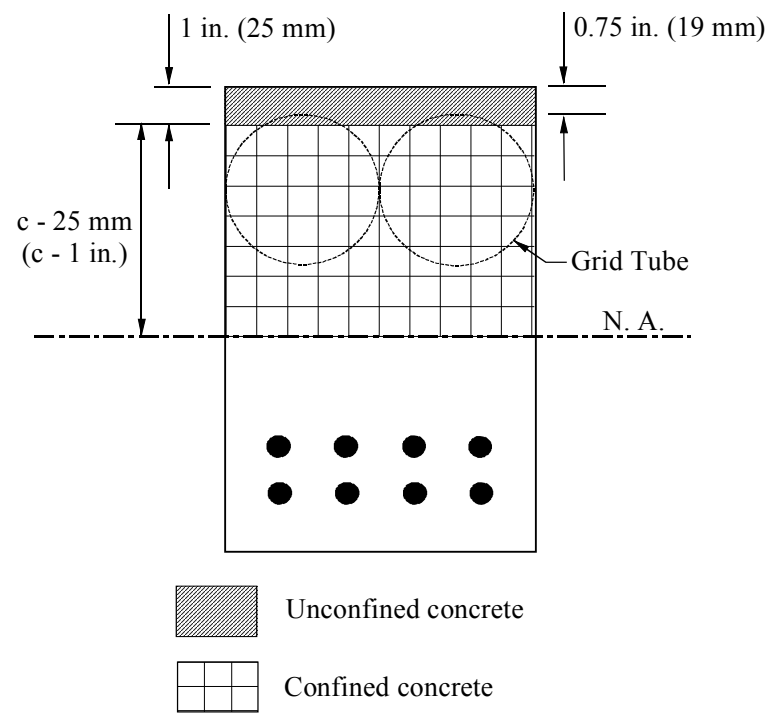

Figure 4: Tube beam cross-section fiber model.

Some of the assumptions employed in this fiber model include perfect bond between concrete and the reinforcing bars (strain compatibility), plain sections remain plain (linear strain distribution), the area below the neutral axis was considered cracked and was ignored in the force and moment calculation and monotonic loading and deformation of the section.

The compressive force in each layer was calculated as the product of the area of the layer and the average stress. The average stress was determined based on the strain in the layer and the stress-strain curves of concrete. The Hognestad parabola was used to calculate the stress-strain curve of unconfined concrete. The modified Hognestad was used to calculate the stress-strain curve of confined concrete [10]. The parameters of the modified Hognestad were determined based on the available data from confined concrete cylinder tests [9].

The tensile force was calculated as the product of the area of steel reinforcement and the steel stress. Steel stress was determined based on the average strain of the two steel layers and by assuming elastic perfectly plastic stress-strain curve.

The moment in the cross-section for the applied curvature distribution was determined by summing moments about the neutral axis.

The moment curvature diagram was calculated by applying increasingly larger top concrete compressive strains $\left(\varepsilon_{\mathrm{c}}\right)$ to the cross-section and varying the location of the neutral axis (c) until equilibrium of the axial forces (zero) in the 
cross-section for the applied strain was achieved. The curvature of the section $(\Phi$ $=\varepsilon_{\mathrm{c}} / \mathrm{c}$ ) was then calculated based on the concrete compressive strain and the location of the neutral axis.

The experimental and fiber model M- $\Phi$ diagrams were calculated for both beams. The theoretical and fiber model M- $\Phi$ diagrams for the control beam (see Figure 5) were approximately the same.

The fiber model M- $\Phi$ behaviour of the tube beam was comparable to the experimental behaviour (see Figure 6). The improvement in the ductility of the

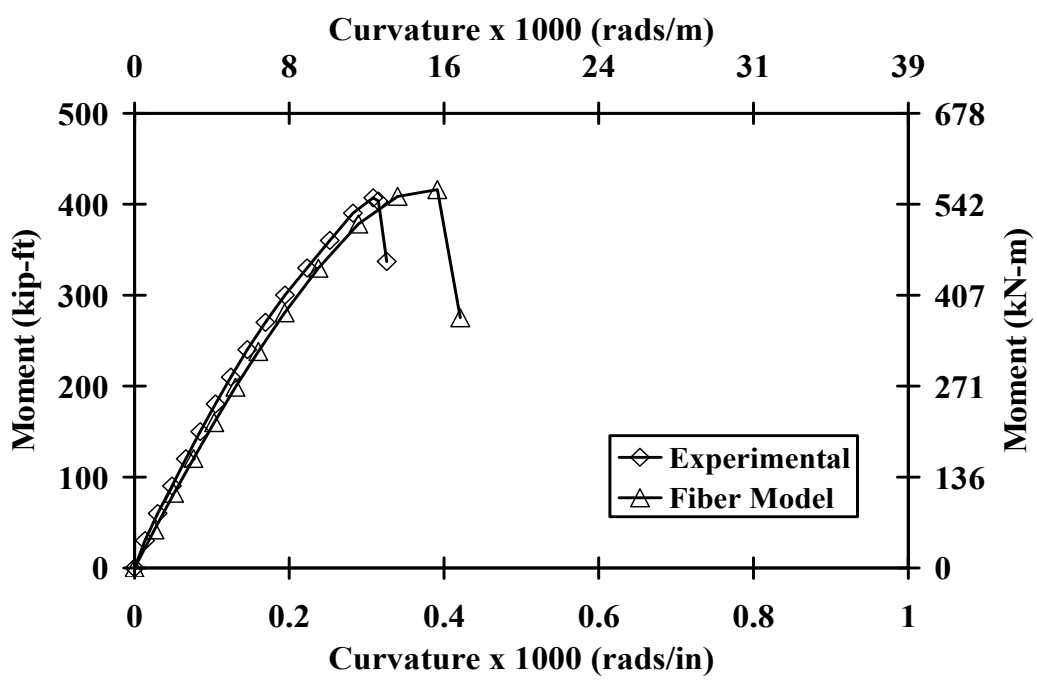

Figure 5: $\quad$ M- $\Phi$ curves for control beam.

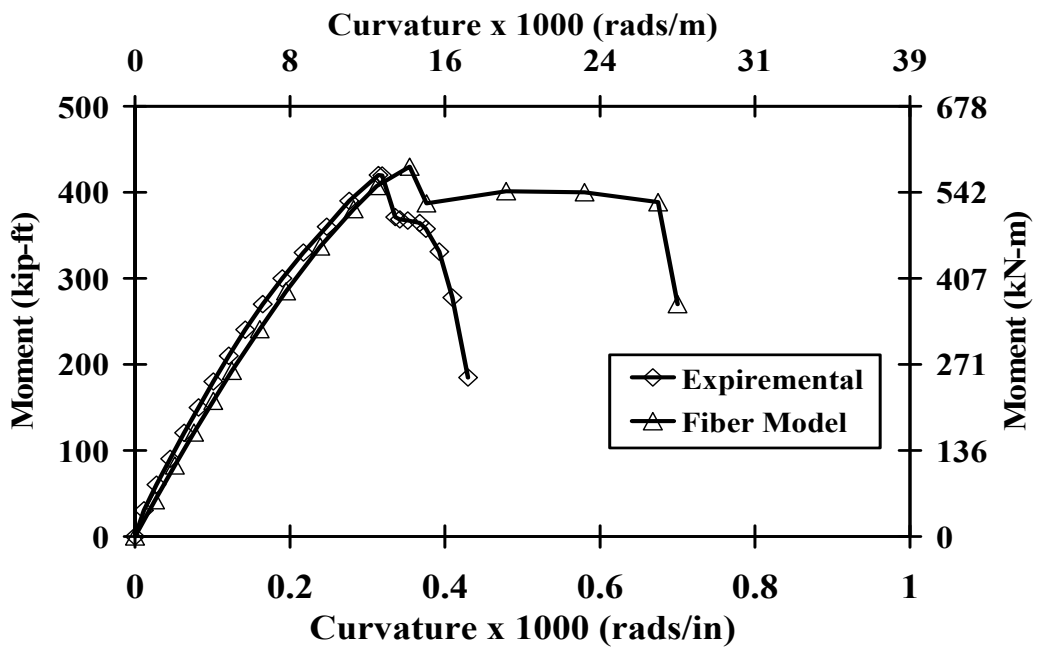

Figure 6: $\quad$ M- $\Phi$ curves for tube beam. 
tube beam compared to the control beam, although relatively small, was evident when the experimental M- $\Phi$ curves for both beams were compared (see Figure 7). The area under the load-displacement curve represents the amount of energy a structure can absorb before failure. The amount of energy is also a good indicator of ductility. Ductile structures usually can absorb higher amounts of energy compared to non-ductile (brittle) structures.

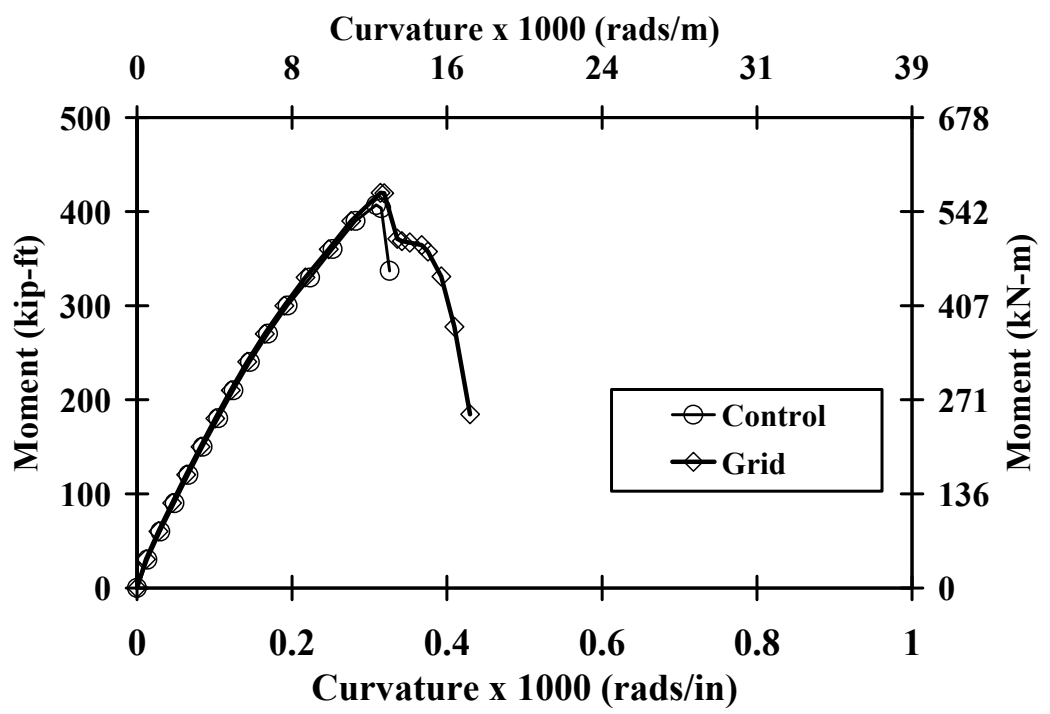

Figure 7: $\quad$ Experimental M- $\Phi$ curves.

The areas under the experimental moment-curvature curves, of both beams, were calculated and compared. The area under the load-displacement curve of the tube beam was approximately $37 \%$ more than that of the control beam. The energy up to peak load was elastic energy while the post peak energy was inelastic. Therefore, the $37 \%$ extra energy was primarily inelastic energy which indicated the ability of the tube beam to undergo inelastic deformation compared to the control beam. This represents an improvement in the ductility of the member and is due to the confining effect of the CFRP composite grid.

Another way to measure ductility is through ductility factors. Curvature ductility factors are a good way to evaluate the ductility of RC members. The curvature ductility factor $\left(\mu_{\Phi}\right)$ is defined as the ratio of the ultimate curvature $\left(\Phi_{u}\right)$ over the curvature at first yield $\left(\Phi_{y}\right)$.

The definition of ultimate and yield curvatures is simple when the behaviour is elasto-plastic. Definition of these parameters is more complicated when the behaviour is not elasto-plastic. Usually the behaviour of reinforced concrete is not perfectly elasto-plastic. Therefore, the need for a consistent definition of the ultimate and yield curvatures was realized. Researchers have proposed definitions of ultimate and yield displacement and curvature as well as instructions on how to calculate them. 
The ultimate curvature has been defined as the curvature at which the lateral load in the descending portion of the load-displacement curve is not less than $80 \%$ of the maximum load $\left(\mathrm{P}_{\mathrm{u}}\right)$ [11-14]. Park and Paulay [15] have argued that the available ultimate deformation (and therefore curvature) is not necessarily the deformation that corresponds to the maximum load capacity. They further argued that "when survival without collapse is the criterion, it is too conservative to define ultimate deformation as the deformation corresponding to the maximum load-carrying capacity. It would seem reasonable to recognize at least some of this deformation capacity after the maximum load has been reached and to define the available ultimate deformation as that deformation when the loadcarrying capacity has reduced by some arbitrary amount after maximum load. For example, a 10 or $20 \%$ reduction in maximum load-carrying capacity could be tolerated in many cases, but the exact amount would depend on the particular case."

The yield displacement (and therefore curvature) can be defined as the displacement at the intersection of the horizontal line representing the ideal lateral capacity, $\mathrm{P}_{\mathrm{i}}$, (nominal capacity using the ACI 318 approach and a reduction factor of unity) and the straight line that passes through zero and the point in the load-displacement curve at $75 \%$ of the ideal lateral capacity [11-13]. The definitions of yield and ultimate displacements are depicted in Figure 8.

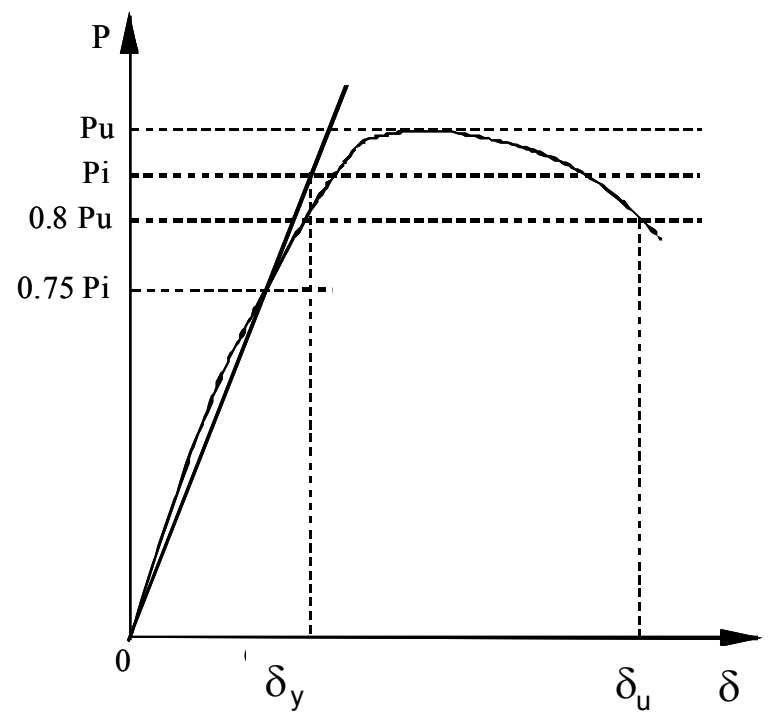

Figure 8: Ductility factor component definitions.

The curvature ductility $\left(\mu_{\Phi}\right)$ was approximately 1.5 and 2 for the control and tube beam respectively. The schematic for determining $\Phi_{u}$ and $\Phi_{c}$ for the control beam is shown in Figure 9. The same approach was used in determining the ductility factor for the tube beam. The curvature ductility factor of the tube beam was approximately $33 \%$ higher than the curvature ductility factor of the control beam. 


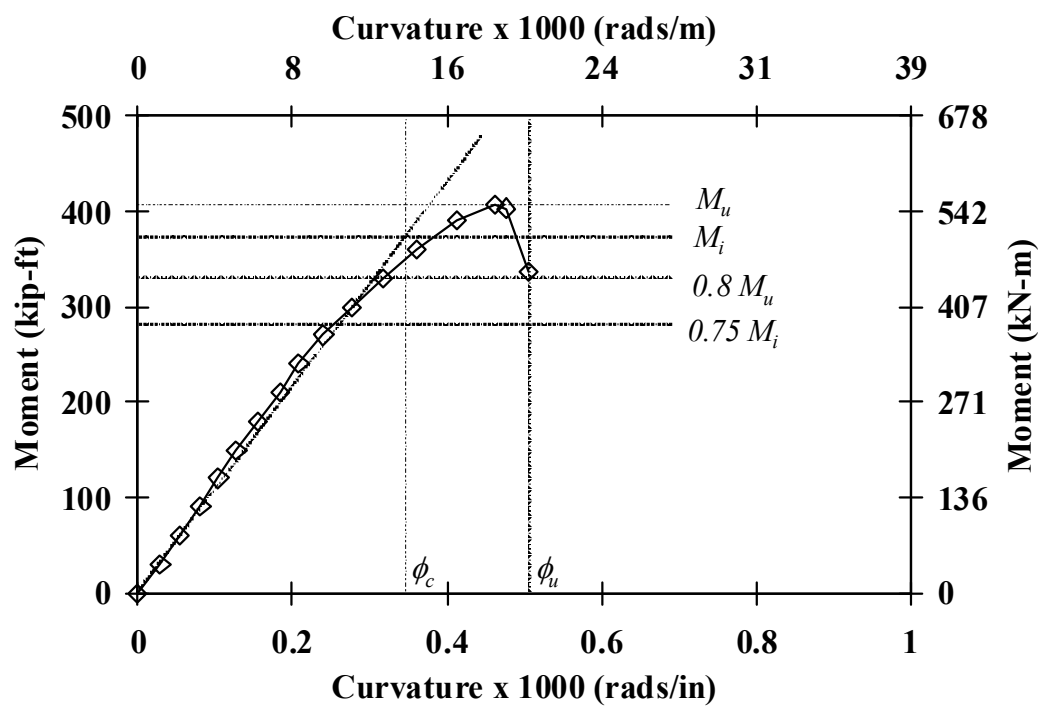

Figure 9: Curvature ductility factor for control beam.

The curvature ductility factor using the fiber model moment-curvature diagram of the control beam was approximately 1.6 which was approximately $4 \%$ higher than the experimental. On the other hand, the curvature ductility factor of the tube beam was approximately 2.45 which was an overestimate of approximately $21 \%$.

\section{Conclusions}

In this paper the development of moment-curvature diagrams for compression controlled RC sections confined with CFRP composite grids was presented. These diagrams were compared with diagrams developed from experimental data for the same sections. Based on the results from this comparison the following conclusions can be drawn:

1. The results from the two beams indicate that the CFRP grid provided confinement to the concrete. Confinement was achieved using a series of small diameter CFRP grid tubes rather than wrapping the entire cross-section.

2. The curvature ductility factor of the beam utilizing the CFRP grid tubes was improved by $33 \%$ compared to the control beam with no grid tubes. The improvement was significant, considering the small amount of CFRP that was used to confine the compression zone.

3. The energy dissipation of the tube beam was $37 \%$ higher compared to the controlled beam due to the effect of concrete confinement. This increase in the energy dissipation of the element also represents an improvement in the ductility due to concrete confinement from the CFRP grid tubes. 
4. The results from the fiber model are fairly accurate compared to the experimental data and therefore the model is considered valid. However, there is a divergence after the peak load and further refinement of the model is required.

5. The number of test specimens is limited and therefore the more testing is required. Due to the small number of test specimens the conclusions are drawn with great caution.

\section{References}

[1] Rooney, J., and Taylor, S., 2004, "Flexural Behaviour of Steel and GFRP Reinforced Concrete Beams," Composites: Part B, Vol. 27, No 3-4, pp. 38-40.

[2] Toutanji, H., and Deng Y., 2003, "Deflection and Crack Width Prediction of Concrete Beams Reinforced with Glass FRP Rods," Construction and Building Materials, Vol. 17, No 1, pp. 69-74.

[3] Grace, N. F., Soliman, A. K., Sayed, G. A., and Saleh, K. R., 1998, "Behavior and Ductility of Simple and Continuous FRP Reinforced Beams," Journal of Composites for Construction, Vol. 2, No 4, pp. 186-194.

[4] Rahman, A. H., Kingsley, C. Y., and Kobayashi, K., 2000, "Service and Ultimate Load Behavior of Bridge Deck Reinforced with Carbon FRP Grid," Journal of Composites for Construction, Vol. 4, No 1, pp. 16-23.

[5] Yost, J. R., Goodspeed, C. H., and Schmeckpeper, E. R., 2001, "Flexural Performance of Concrete Beams Reinforced with FRP Grids," Journal of Composites for Construction, Vol. 5, No 1, pp. 18-25.

[6] Harries, K. A., and Gassman, S. L., 2003, "Load Tests of Reinforced Concrete Catch Basing Knockout Panels," Department of Civil and Environmental Engineering, University of South Carolina, Report No ST03-01, p. 21.

[7] Shao, Y., Johnson, C., and Mirmiran, A., 2003, "Control of Plastic Shrinkage Cracking of Concrete with TechFab Carbon FRP Grids," Department of Civil, Construction, and Environmental Engineering, North Carolina State University, Report to Tech-Fab Inc, p.

[8] Hamilton, H. R, Cook, R. A., and Alfonzo, L., 2006, "Crack Control in Toppings for Precast Flat Slab Bridge Deck Construction," Department of Civil and Coastal Engineering, University of Florida, Engineering and Industrial Station, Final Report Submitted to FDOT, UF Project No 00030907, p. 120.

[9] Michael, A. P., Hamilton, H. R. III, and Ansley, M. H. (2005). "Concrete confinement using carbon fiber reinforced polymer grid", American Concrete Institute, SP230-56, Vol. 230, pp. 991-1010.

[10] Park, R., and Paulay, T., 1975 (a), "Chapter 6: Ultimate Deformation and Ductility of Members with Flexure," Reinforced Concrete Structures, John Wiley \& Sons, New York, NY, pp. 195-269. 
[11] Priestley, M. J. N., and Park, R., 1987, "Strength and Ductility of Concrete Bridge Columns under Seismic Loading," ACI Structural Journal, Vol. 84, No 1, pp. 61-76.

[12] Zahn, F. A., Park, R., and Priestley, M. J. N., 1990, "Flexural Strength and Ductility of Circular Hollow Reinforced Concrete Columns without Confinement on Inside Face," ACI Structural Journal, Vol. 87, No 2, pp. 156-166.

[13] Sheikh, S. A., and Khoury, S. S., 1993, "Confined Concrete Columns with Stubs," ACI Structural Journal, Vol. 90, No 4, pp. 414-431.

[14] Yeh, Y. K., Mo, Y. L., and Yang, C. Y., 2002, "Seismic Performance of Rectangular Hollow Bridge Columns," Journal of Structural Engineering, Vol. 128, No 1, pp. 60-68.

[15] Park, R., and Paulay, T., 1975 (b), "Chapter 11: Strength and Ductility of Frames," Reinforced Concrete Structures, John Wiley \& Sons, New York, NY, pp. 496-609. 